\title{
Tracking fish with electronic tags
}

The distributions of many species of fish show pronounced seasonal changes as a result of migration ${ }^{1}$. We are using longterm electronic tagging to study the migratory behaviour of fish in the North Sea. Using simple measurements of depth and temperature, we have found that we can reconstruct the tracks of plaice (Pleuronectes platessa) migrating between the southern North Sea and their spawning areas in the eastern English Channel or northeast coast of England. In this way we show that fish can visit more than one spawning area within a single spawning season and that rates of movement are often ten times faster than those deduced from conventional mark- recapture experiments.

In the North Sea, plaice, cod and several other species migrate by selective tidal stream transport ${ }^{2-6}$. Fish leave the sea bed at or shortly after slack water, swim up into midwater and are carried downstream by the tide before returning to the bottom about six hours later. Maturing fish use one tidal stream to reach their spawning grounds; fish that have spawned use the opposing stream to return to their feeding grounds ${ }^{7}$.

Until recently we have only been able to

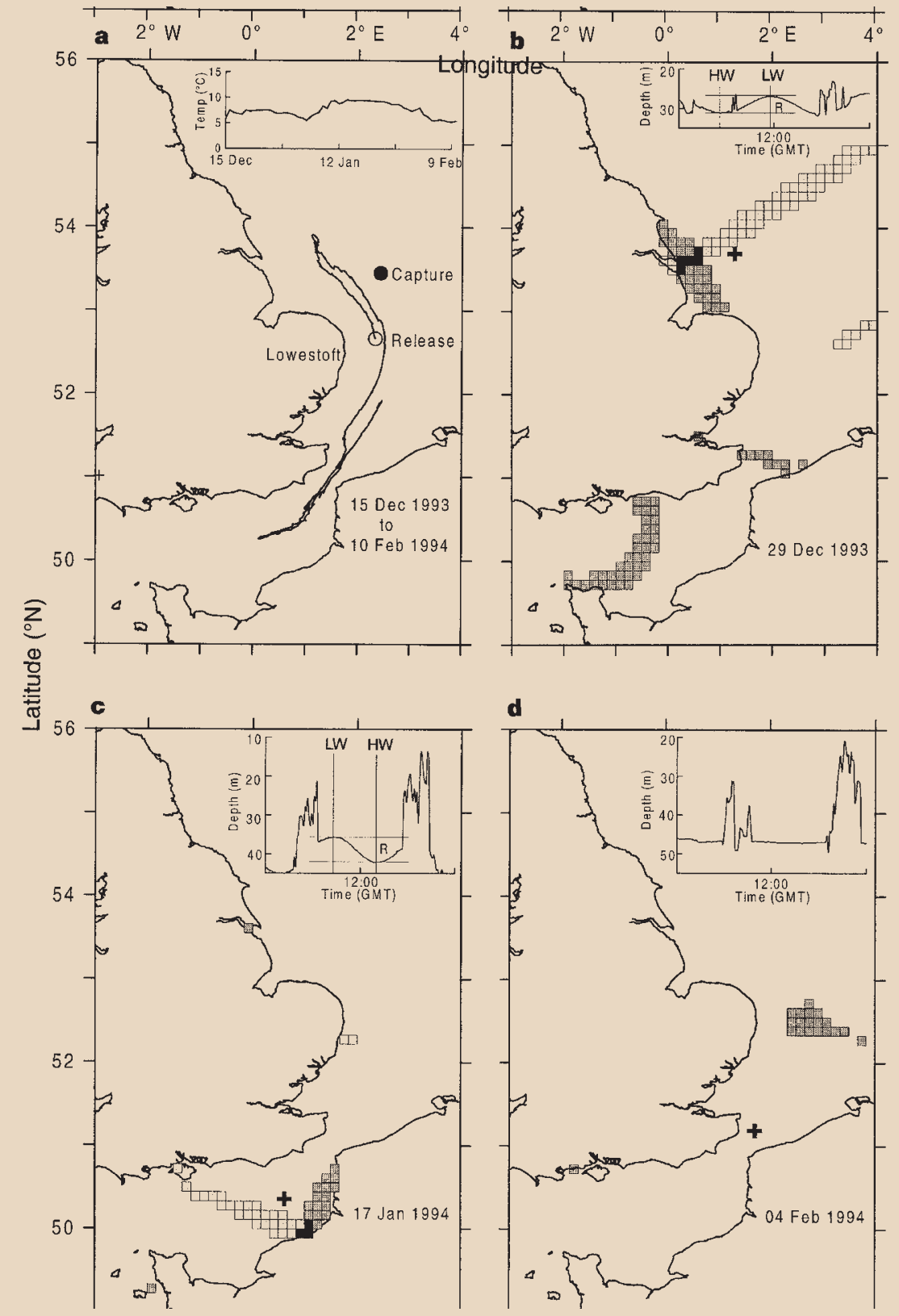

track individual fish for a few days at a time using a research vessel, sonar and acoustic tags. Now our engineers have developed an electronic tag that records depth $(0-100 \mathrm{~m}$ $\pm 0.2 \mathrm{~m}$ ) and water temperature ( -4 to 23 ${ }^{\circ} \mathrm{C} \pm 0.03{ }^{\circ} \mathrm{C}$ ), allowing us to observe over long periods and replicate our observations. The Mk 1 tag, which was specifically designed for flat-fish, stores 32,000 data samples and weighs about $55 \mathrm{~g}$ in air $(23 \mathrm{~g}$ in sea water). The Mk 3 tag, which can be used on roundfish as well as flat-fish, is smaller (16 g in air), can store over 500,000 data samples and also records light intensity.

We attached $303 \mathrm{Mk} 1$ tags to large (over $40 \mathrm{~cm}$ long) maturing female plaice in the southern North Sea between December 1993 and February 1997. Thirty-seven tags have so far been returned through the commercial fishery, producing 1,946 days of data. Nine tags recorded continuously for over 100 days and 3 for over 200 days; one tag was returned after 300 days at sea. Several fish spawned whilst at liberty, and it seems that large plaice can tolerate the Mk 1 tags for long periods without migration or spawning being seriously inhibited.

Figure $1 \mathrm{a}$, The reconstructed track for a maturing female plaice ( $48 \mathrm{~cm}$ long) tagged with a Mk 1 data storage tag (DST 08). b-d, Independent confirmation of geographical location at 3 positions based on measurements of tidal range $(R)$ and times of high water (HW) recorded by the tag (insets). Independent estimates of location (crosses) were obtained with the Proudman Oceanographic Laboratory's numerical storm-surge model ${ }^{12}$, which calculates tidal data on a $12-\mathrm{km}$ grid. This model was used to identify areas of similar $( \pm 0.4 \mathrm{~m}$ ) tidal range (dark stipple) and similar ( \pm 10 minutes) times of HW (light stipple) to those recorded by the tag (congruent areas are indicated in black). In the North Sea, the tidal wave rotates around three amphidromes (points of no tide where $R=0$ ). Geographical location is obtained from bi-coordinate grids formed by co-tidal lines (linking points with the same tidal phase) radiating from the amphidromes and corange lines (linking points of equal tidal range) centred on the amphidromes. The absence of a sinusoidal tidal wave (inset in d) shows that the fish was close to the amphidrome at $52^{\circ} 30^{\prime} \mathrm{N}, 03^{\circ} 03^{\prime} \mathrm{E}$ on 4 February. Comparison of the daily record of seawater temperature with synoptic charts of sea surface temperature (Bundesamt für Seeschiffahrt und Hydrographie, Hamburg) provides a further check on geographical location. The temperature record (inset in a) shows that the fish spent 12 days in water warmer than $9^{\circ} \mathrm{C}$, a temperature observed in the eastern Channel, but not the North Sea during January and February 1994. 
The track of one plaice, caught on 10 February 1994 after 56 days, demonstrates the information we can obtain with the new tags. Although release and recovery positions were only $88 \mathrm{~km}$ apart, the reconstructed track (Fig. 1a) shows that the fish travelled more than $900 \mathrm{~km}$, first moving north to the Flamborough Off Ground and then south to the eastern English Channel - both important spawning grounds for plaice - before being caught by a Dutch trawler in the southern North Sea. This result was most unexpected, as it is usually assumed that plaice are faithful to one spawning ground, at least within a single spawning season. The track reconstruction ${ }^{8}$ assumes that the fish migrated by selective tidal stream transport ${ }^{2}$, and that, when off the bottom, swam downstream at an average speed of 0.6 body lengths per second ${ }^{9}$, while being carried over the ground by the tide. The track is confirmed by independent estimates of geographical position obtained from depth measurements made when the fish was stationary on the sea bed for one or more tidal cycles (Fig. 1b-d), and by a comparison of local sea temperature with recordings from the tag (Fig. 1a).

Nine of the 17 tracks we have reconstructed so far show substantial migrations south into the eastern English Channel or north along the east coast of England. Three tracks show two or more reversals similar to those described above, and the temperature and hydrostatic data again provide independent confirmation of the scale of movement. The tracks show that individual fish can move rapidly over large distances and suggest that migration rates (over $20 \mathrm{~km}$ per day where tidal streams are fast) can often be ten times faster than those deduced from mark-recapture experiments ${ }^{10}$.

Our findings illustrate how observations of individual fish can shed new light on the behaviour of exploited populations. The results are relevant to questions of stock identity and the definition of biologically realistic quota areas; they also provide a basis for assessing the impact of technical conservation measures. Closed areas, which are already used to underpin quota management within the European common fisheries policy ${ }^{10}$, have recently been suggested as a method of managing cod in the northwest Atlantic following the catastrophic collapse of the Newfoundland fishery $^{11}$. In addition to practical applications, the data provide new insights into the environmental cues used by migratory fish and the sensory systems underlying their sophisticated patterns of behaviour.

\section{J. D. Metcalfe, G. P. Arnold}

Centre for Environment, Fisheries and Aquaculture Science,

Lowestoft Laboratory, Lowestoft,

Suffolk NR33 OHT, UK

e-mail: j.d.metcalfe@cefas.co.uk
1. Harden Jones, F. R. Fish Migration (Arnold, London, 1968).

2. Greer Walker, M., Harden Jones, F. R. \& Arnold, G. P. J. Cons. Int. Explor. Mer 38, 58-86 (1978).

3. de Veen, J. F. Neth. J. Sea Res. 12, 115-147 (1978).

4. Arnold, G. P. in Animal Migration (ed. Aidley, J. D.) 55-79 (Cambridge Univ. Press, 1981).

5. Rijnsdorp, A. D., von Stralen, M. \& van Veer, H. W. Trans. Am Fish. Soc. 114, 461-470 (1985).

6. Arnold, G. P., Greer Walker, M., Emerson, L. S. \& Holford, B. H. ICES J. Mar. Sci. 51, 207-232 (1994).

7. Arnold, G. P. \& Metcalfe, J. D. Mar. Biol. 127, 151-160 (1996).

8. Arnold, G. P. \& Holford, B. H. ICES J. Mar. Sci. 52, 981-990 (1995).

9. Metcalfe, J. D., Arnold, G. P. \& Webb, P. W. J. Mar. Biol. Assoc. UK 70, 149-162 (1990).

10. Rijnsdorp, A. D. \& Pastoors, M. A. ICES J. Mar. Sci. 52, $963-980$ (1995).

11. Walters, C. \& Maguire, J.-J. Rev. Fish Biol. Fish. 6, 125-137 (1996).

12. Flather, R., Proctor, R. \& Wolf, J. in Computer Modelling in the Environmental Sciences (eds Farmer, D. G. \& Rycroft, M. J.) 15-30 (Clarendon, Oxford, 1991).

\section{Long-term potentiation in awake mutant mice}

The relationship between long-term potentiation (LTP) and spatial learning has been explored in a variety of genetically engineered mice with deletions of specific genes ${ }^{1}$. With few exceptions, LTP in these animals has been studied in the hippocampal slice preparation. The conditions required to elicit LTP in vitro, however, may not be comparable to those in the intact animal.

LTP is readily induced in the dentate gyrus of the anaesthetized or awake rat, but its induction in vitro requires the addition of a $\mathrm{GABA}_{\mathrm{A}}$ antagonist such as bicuculline to the bathing medium ${ }^{2}$. In mice lacking the cell-adhesion molecule Thy-1, we were unable to elicit LTP in the dentate gyrus of the anaesthetized mouse, whereas in vitro, with inhibition by GABA suppressed, the magnitude of LTP was the same in
Thy-1 $1^{-1-}$ and wild-type littermates ${ }^{3}$. By adding bicuculline to the solution in the recording pipette, however, we were able to 'rescue' LTP in the dentate gyrus of the anaesthetized Thy-1 $1^{-1-}$ mouse.

These observations raise the question whether LTP can be induced in the dentate gyrus of the awake, freely moving Thy-1 $1^{-1-}$ mouse. Thy $-1^{-1-}$ mice show no deficit in performance in the Morris water maze, and our previous results in the anaesthetized animal suggest that LTP in the dentate gyrus may not be necessary for spatial learning. We have developed techniques to monitor LTP in the awake mouse ${ }^{4}$, and have now examined ten $T h y-1^{-1-}$ mice and five control mice (two wild-type and three heterozygotes) from the same breeding colony as the earlier study ${ }^{3}$.

Under pentobarbitone anaesthesia, we placed a stimulating electrode in the angular bundle to activate perforant path fibres projecting to granule cells, and a recording electrode in the hilus of the dentate gyrus to monitor evoked field responses (see ref. 4 for details). Evoked responses were recorded through a miniaturized headstage.

Animals were allowed to recover for a week. During the following week they were handled daily, and familiarized with the recording box. In the third week, evoked potentials were sampled daily. After stable responses had been recorded for two days, tetanic stimulation was applied, and the effect on the evoked response monitored over the next three days. At the end of the testing period, tail clips were taken for genetic typing ${ }^{3}$.

Although the average magnitude of LTP in the awake Thy-1 knockouts is significantly lower than in control animals (Fig. 1a), unambiguous LTP was nevertheless observed in 5 of 10 knockout animals (Fig. 1b). This contrasts with the situation in the anaesthetized animal, where we observed
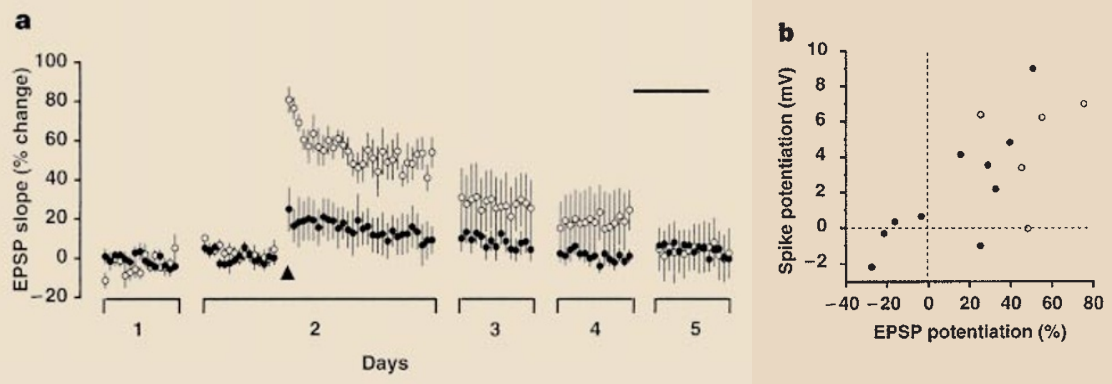

Figure $1 \mathbf{a}$, Slope of the field EPSP evoked in the dentate gyrus in Thy-1 $1^{-1-}$ mice ( $n=10$, filled circles), and in control littermates ( $n=5$, open circles). Baseline responses evoked by test stimuli at $0.033 \mathrm{~Hz}$ were measured on 2 days, after which a tetanus ( 6 series of 6 trains of 6 stimuli at $400 \mathrm{~Hz} ; 100 \mathrm{~ms}$ between trains, $20 \mathrm{~s}$ between series) was delivered (arrow). Responses to the test intensity were measured for 60 min after LTP induction, and for 30 min each on the next three days. Each point represents the mean of 4 consecutive responses normalized to the mean baseline value. Bar represents $30 \mathrm{~min}$. The magnitude of LTP in Thy-1 $1^{-1-}$ mice was significantly less than in controls only on the day of induction $(P<0.05$, ANOVA). b, LTP in the dentate gyrus of individual Thy-1 $1^{-1-}$ (closed circles) and control (open circles) mice, plotted as mean absolute change in population spike amplitude, measured 30-60 min after tetanus, against the corresponding percentage change in EPSP slope. 